\title{
The influence of platform switching on the biomechanical aspects of the implant-abutment system. A three dimensional finite element study
}

\author{
Luigi Canullo $^{1}$, Francesco Pace ${ }^{2}$, Paulo Coelho ${ }^{3}$, Enrico Sciubba ${ }^{4}$, Iole Vozza ${ }^{5}$
}

${ }^{1}$ DDS, Department of Endodontics, University of Chieti “G. D’Annunzio”, School of dentistry, Private Practice, Roma, Italy

${ }^{2}$ M.Eng, Department of Mechanical \& Aeronautical Engineering, University of Rome "La Sapienza”, Rome, Italy

${ }^{3}$ DDS, M.Eng., Ph.D, Department of Prosthodontics, "Sapienza" University of Rome,Rome, Italy

${ }^{4}$ M.Eng., Ph.D, Department of Mechanical \& Aeronautical Engineering, University of Rome "La Sapienza", Rome, Italy

${ }^{5}$ DDS, Ph.D, Department of Biomaterials and Biomimetics, New York University, New York, USA

Correspondence:

via Nizza 46, 00198 Roma, Italy

luigicanullo@yahoo.com

Received: $11 / 08 / 2010$

Accepted: 06/09/2010
Canullo L, Pace F, Coelho P, Sciubba E, Vozza I. The influence of platform switching on the biomechanical aspects of the implant-abutment system. A three dimensional finite element study. Med Oral Patol Oral Cir Bucal. 2011 Sep 1;16 (6):e852-6.

http://www.medicinaoral.com/medoralfree $01 / \mathrm{v} 16 \mathrm{i} 6 /$ medoralv16i6p852.pdf

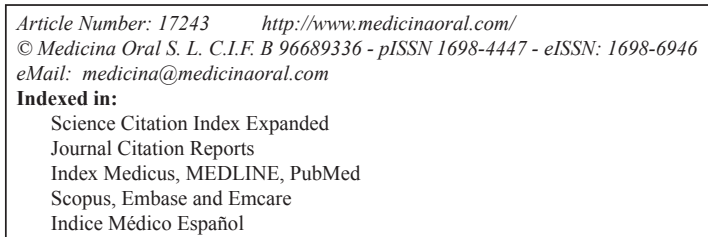

\begin{abstract}
Objective: To evaluate the biomechanical scenario of platform switching geometric implant-abutment configuration relative to standard configurations by means of finite element analysis.

Study Design: A 3D Finite Element Analysis (FEA) was performed on 3 different implant-abutment configurations: a $3.8 \mathrm{~mm}$ implant with a matching diameter abutment (Standard Control Design, SCD), a $5.5 \mathrm{~mm}$ implant with matching diameter abutment (Wider Control Design, WCD), and a $5.5 \mathrm{~mm}$ implant with a $3.8 \mathrm{~mm}$ abutment (Experimental Design, ED). All the different experimental groups were discretized to over 60000 elements and 100000 nodes, and 130N vertical (axial) and 90N horizontal loads were applied on the coronal portion of the abutment. Von Mises stresses were evaluated and maximum and minimum values were acquired for each implantabutment configuration.

Results: The load-induced Von Mises stress (maximum to minumum ranges) on the implant ranged from 150 $\mathrm{MPa}$ to $58 \mathrm{~Pa}$ (SCD); $45 \mathrm{MPa}$ to $55 \mathrm{~Pa}$ (WCD); $190 \mathrm{MPa}$ to $64 \mathrm{~Pa}$ (ED). The Von Mises stress on the abutment ranged from $150 \mathrm{MPa}$ to $52 \mathrm{MPa}$ (SCD); $70 \mathrm{MPa}$ to $55 \mathrm{MPa}$ (WCD), and $85 \mathrm{MPa}$ to $42 \mathrm{MPa}$ respectively (ED). The maximum stresses transmitted from the implant-abutment system to the cortical and trabecular bone were $67 \mathrm{~Pa}$ and $52 \mathrm{MPa}$ (SCD); $54 \mathrm{~Pa}$ and $27 \mathrm{MPa}$ (WCD); $64 \mathrm{~Pa}$ and $42 \mathrm{MPa}$ (ED), respectively. When the implant body was evaluated for stresses, a substantial decrease in their levels were observed at the threaded implant region due to the diametral mismatch between implant and abutment for the ED configuration.

Conclusion: The platform switching configuration led to not only to a relative decrease in stress levels compared to narrow and wide standard configurations, but also to a notable stress field shift from bone towards the implant system, potentially resulting in lower crestal bone overloading.
\end{abstract}

Key words: Platform switching, bone mechanical response, finite element analysis, implant-abutment stress. 


\section{Introduction}

Any estimation of prosthetic systems reliability should consider biological, chemical, biomechanical, and patient-related aspects. The biomechanical aspects are important in the evaluation of the risk of bone resorption that affects the stability efficiency of the prosthesis over time (1).

After implant insertion and its subsequent initial loading, crestal bone undergoes remodelling and resorption (2). The mechanism of bone resorption is presently attributed to a biologic width reestablishment that follows a chronic bacterial inflammation of the implant/abutment connection (3). Additional bone resorption seems to be related to micro-movements at the abutment-implant interface and occlusal loading (4).

Several reports have suggested improved crestal bone maintenance over time for platform-switched restored implants (5-8). These results appear to be related to an horizontally re-established biological width, as previously described in the literature (9).

A recently published review and meta-analysis showed that platform switching may preserve the inter-implant bone height and soft tissue levels (10). The degree of marginal bone resorption was inversely related to the extent of implant abutment mismatch (11).

Platform switched implants are also known to preserve marginal bone from stress concentration, mostly localized in the proximal layer between implant and abutment $(12,13)$.

As finite element analysis (FEA) has been extensively and successfully employed in an attempt to predict biomechanical performance of various dental implant designs $(14,15)$, the aim of this study was to evaluate the biomechanical scenario of platform switching geometric implant-abutment configuration relative to standard configurations by means of finite element analysis. For this purpose, platform switched implant-abutment configurations were compared to implant-abutment configurations with matching diameters.

\section{Materials and Methods}

FEA was performed on 3 implant-abutments configurations: a $3.8 \mathrm{~mm}$ implant with a matching diameter abutment (Implant U380-MDPC380, Standard Control Design, SCD), a $5.5 \mathrm{~mm}$ implant with matching diameter abutment (Implant U550-MDPC550, Wider Control Design, WCD) and a $5.5 \mathrm{~mm}$ implant with a $3.8 \mathrm{~mm}$ abutment (Implant U550-MDPC380, Experimental Design, Ed). The implant geometry was digitally imported using CAD-generated IGS files into the Ansys ${ }^{\circledR}$ Workbench software that was also used to calculate the local stresses.

They were considered:

1. Cortical bone, superficial bone tissue with $2 \mathrm{~mm}$ thickness, $15 \mathrm{GPa}$ Young's modulus and 0.35 Poisson's ratio.
2. Cancellous bone, inner bone tissue with $1.5 \mathrm{GPa}$ Young's modulus and 0.30 Poisson's ratio.

A proper set of drawings of the implant (Global Implant $^{\mathbb{Q}}$, Sweden \& Martina, Padova, Italy), including coronal micro-grooving and the internal connection, was discretised by a mesh with over 60.000 elements and 100.000 nodes.

The calculation domain included a rather extended portion of bone tissue: the zero-displacement boundary conditions were imposed on the external bone boundaries. Loads were applied on the coronal portion of the abutment: the axial load (z-direction) was $130 \mathrm{~N}$ and the transversal load, responsible for both shearing and bending strain, was $90 \mathrm{~N}$. The software output evaluated was the Von Mises stress range for each solid (abutment, implant, cortical, and cancellous bone).

\section{Results}

All Von Mises Stresses for the implant, abutment, cortical, and cacellous bone solids obtained for the SCD, WCD, and Ed are presented in Table 1.

\section{-SCD Implant}

The highest stress area was found around the periphery of the implant upper surface, along its lateral surface, at the level of micro-threads and on the bone facing that area.

The load-induced stress ranged from $150 \mathrm{MPa}$ in the external implant portion, near the micro-threads, to 58 $\mathrm{Pa}$, in the abutment (Fig. 1.A). The von Mises stress on the abutment ranged from $150 \mathrm{MPa}$ (connection portion where the overall stress is a compression) to $52 \mathrm{MPa}$ (coronal part). The stresses transmitted from the implant to the cortical and cancellous bones were $52 \mathrm{MPa}$ and $67 \mathrm{~Pa}$, respectively (Fig. 1.B). $67 \mathrm{~Pa}$ was assessed on the implant apex.

\section{-WCD Implant}

The highest stress area was found around the periphery of the implant/abutment interface but it was smaller than in the previous configuration. The load-induced stress ranged from $45 \mathrm{MPa}$ to $55 \mathrm{~Pa}$ (Fig. 2.A). The von Mises stress on the abutment ranged from $70 \mathrm{MPa}$ to $55 \mathrm{MPa}$. The stresses transmitted from the implant to the cortical and cancellous bones were $24 \mathrm{MPa}$ and $57 \mathrm{~Pa}$, respectively (Fig. 2.B). $54 \mathrm{~Pa}$ was assessed on the implant apex.

\section{-ED Implant}

The highest stress area is shifted toward to the center of the implant bulk, and negligible stress levels were found at the level of micro-threads and on the bone facing that area. The load-induced stress ranged from 190 MPa to $64 \mathrm{~Pa}$ (Fig. 3.A). The von Mises stress on the abutment ranged from $85 \mathrm{MPa}$ to $42 \mathrm{MPa}$. The stresses transmitted from the implant to the cortical and cancel lous bones were $42 \mathrm{MPa}$ and $64 \mathrm{~Pa}$, respectively (Fig. 3.B). $64 \mathrm{~Pa}$ was assessed on the implant apex. No deformation appeared in the threaded part of implant and at the implant/bone interface. 
Table 1. Comparison between stress distribution on experimental groups.

\begin{tabular}{|l|l|l|l|}
\cline { 2 - 4 } \multicolumn{1}{l|}{} & SCD & WCD & ED \\
\hline Max & $237 \mathrm{MPa}$ & $68 \mathrm{MPa}$ & $192 \mathrm{MPa}$ \\
\hline Min & $67 \mathrm{~Pa}$ & $54 \mathrm{~Pa}$ & $48 \mathrm{~Pa}$ \\
\hline Micro-threads & $113 \mathrm{MPa}$ & $40 \mathrm{MPa}$ & $40 \mathrm{MPa}$ \\
\hline $\begin{array}{l}\text { Cortical bone } \\
\text { Cancellous } \\
\text { bone }\end{array}$ & $78 \mathrm{MPa}$ & $40 \mathrm{MPa}$ & $30 \mathrm{MPa}$ \\
\hline
\end{tabular}

Max: maximum stress

Min: minimum stress

Micro-threads: stress mean value at micro-grooving portion of the fixture

Cortical bone: stress mean value on the cortical bone

Cancellous bone: stress mean value on the Cancellous bone

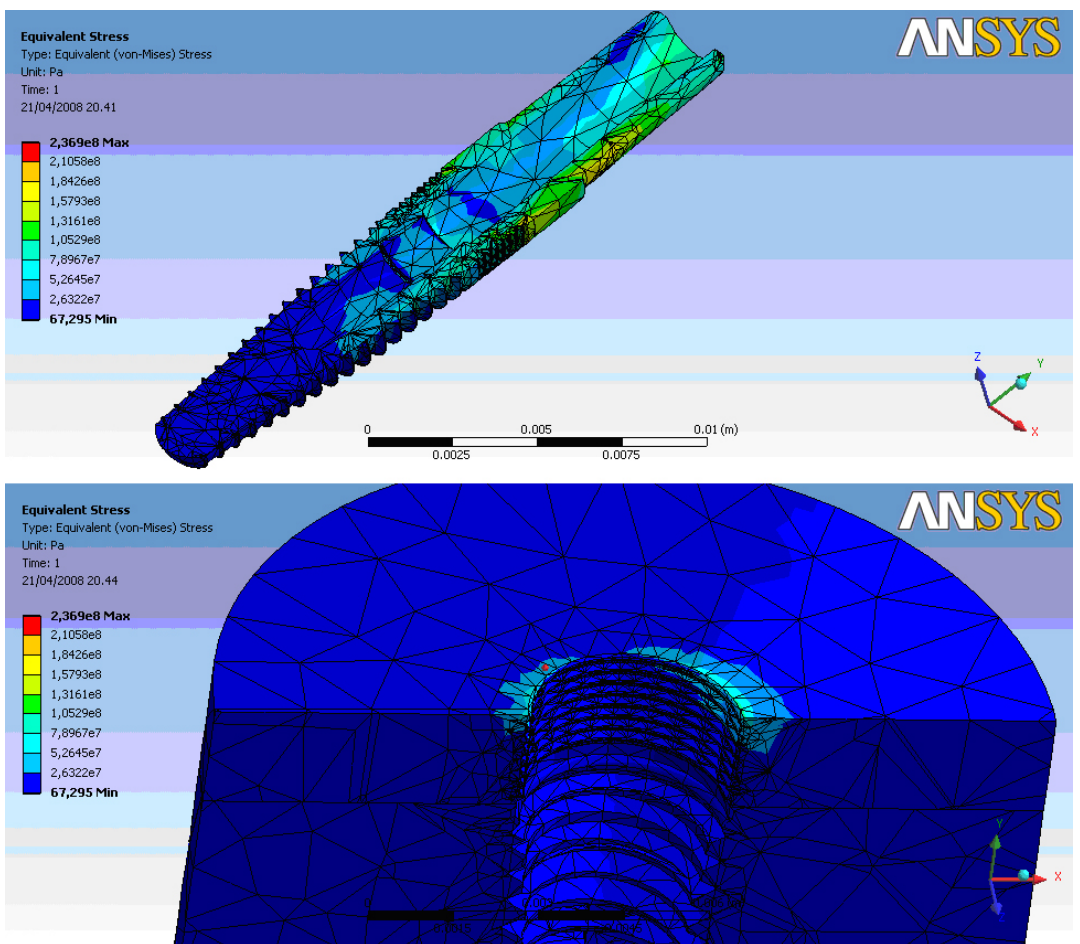

Fig. 1. A) Calculated Von Mises stress for the SCD configuration (axial section). B) Stress on bone tissues around the SCD configuration (axial section). 


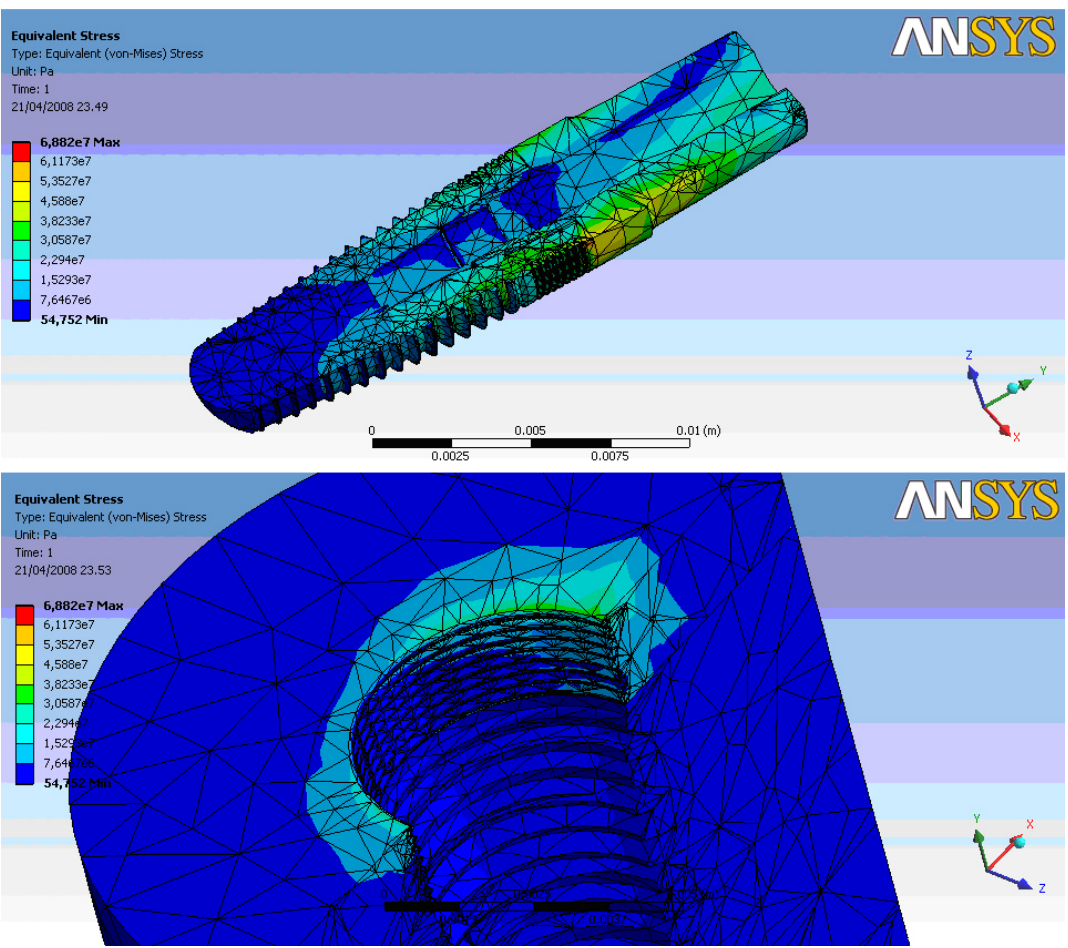

Fig. 2. A) Calculated Von Mises stress for the WCD configuration (axial section). B) Stress on bone tissues around the WCD configuration (axial section).

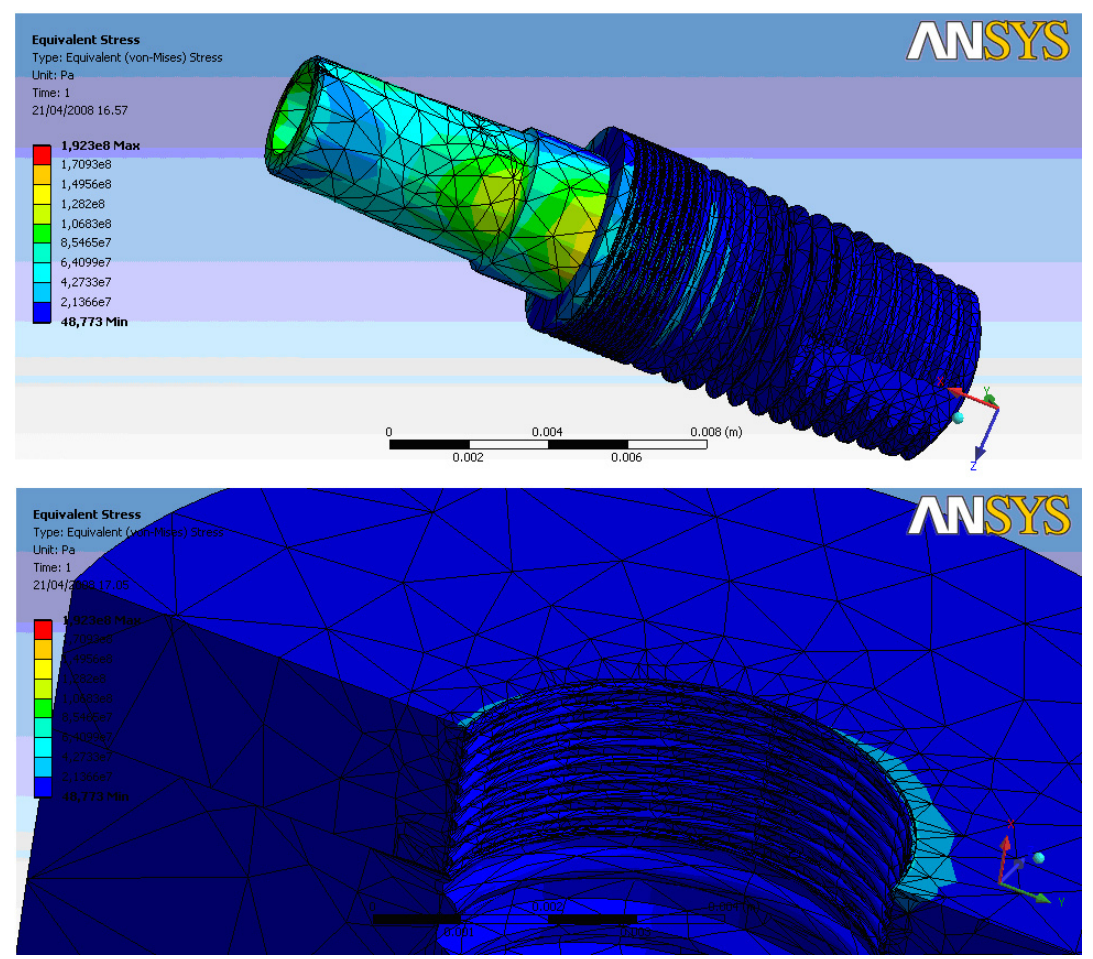

Fig. 3. A) Calculated Von Mises stress for the ED configuration (axial section). B) Stress on bone tissues around the ED configuration (axial section). 


\section{Discussion}

Accurate determination of the biomechanical scenario in the bone tissue surrounding implants is an experimental challenge, and these have been in the past performed by a variety of methods including photoelasticity, strain gauge placement, and finite element analysis. Concerning finite element analysis, the ever evolving software and hardware capabilities provide researchers with new capabilities and tools in short periods of time, allowing for rapid refinement of previous results and thereby the ability to examine nuances not evidenced in previous studies. In comparison with previous studies $(12,13)$, the present investigation adopted a finer geometric resolution of the implant, thus allowing for a more detailed assessment of the stress distribution on both implant, abutment, and bone. The implant geometric configuration utilized for the present study present micro-threads on the medial portion leading to a further improvement in the distribution of mechanical stresses because of the locally "fractal-like" geometry . This is in accordance with other clinical observations (11), which have demonstrated that different implant diameters result in different degrees of occlusal stress dissipation.

Even though the literature in the topic is under development, it is general consensus that bone resorption can be reduced when the abutments are smaller than the diameter of the implant body ('platform switching') (5-11, $15,16)$. In agreement with recently published studies (17-20), our results showed that the ED configuration minimized the stresses at the implant/abutment interface region. In addition, the observed stress reduction on the coronal part of bone tissue brought about by the ED configuration with respect to SCD and to WCD configuration amounted to $160 \%$ and $33 \%$ respectively. For the ED, due to the reduced diameter abutment, stresses are concentrated on the implant fixture rather than on the bone tissues as observed for the SCD and WCD.

Where the stress level on the micro-threaded region of the implant in cortical bone is concerned, due to the wider diameter of both the ED and the WCD, presented a $200 \%$ stress reduction in comparison to the Traditional Control fixture.

Considering the result obtained in the present study altogether, this study shows that platform switching leads to a decrease stress transferred onto peri-implant bone due to a shift in the implant-abutment component stress distribution. However, it must be understood that simplifying modeling assumptions typically utilized for bone as homogeneous material properties utilized warrants validation of the observed results in controlled clinical studies.

\section{References with links to Crossref - DOI}

\section{References}

1. Kitamura E, Stegaroiu R, Nomura S, Miyakawa O. Biomechanical aspects of marginal bone resorption around osseointegrated implants: considerations based on a three-dimensional finite element analysis. Clin Oral Implants Res. 2004;15:401-12.

2. Roos J, Sennerby L, Lekholm U, Jemt T, Gröndahl K, Albrektsson T. A qualitative and quantitative method for evaluating implant success: a 5-year retrospective analysis of the Brånemark implant. Int J Oral Maxillofac Implants. 1997;12:504-14.

3. Broggini N, McManus LM, Hermann JS, Medina R, Schenk RK, Buser D, et al. Peri-implant inflammation defined by the implantabutment interface. J Dent Res. 2006;85:473-8.

4. Isidor F. Influence of forces on peri-implant bone. Clin Oral Implants Res. 2006;17Suppl 2:8-18.

5. Vigolo P, Givani A. Platform-switched restorations on wide-diameter implants: a 5-year clinical prospective study. Int J Oral Maxi1lofac Implants. 2009;24:103-9.

6. Canullo L, Rasperini G. Preservation of peri-implant soft and hard tissues using platform switching of implants placed in immediate extraction sockets: a proof-of-concept study with 12- to 36-month follow-up. Int J Oral Maxillofac Implants. 2007;22:995-1000.

7. Vela-Nebot X, Rodríguez-Ciurana X, Rodado-Alonso C, SegalàTorres M. Benefits of an implant platform modification technique to reduce crestal bone resorption. Implant Dent. 2006;15:313-20.

8. Canullo L, Quaranta A, Teles RP. The microbiota associated with implants restored with platform switching: a preliminary report. J Periodontol. 2010;81:403-11.

9. Lazzara RJ, Porter SS. Platform switching: a new concept in implant dentistry for controlling postrestorative crestal bone levels. Int J Periodontics Restorative Dent. 2006;26:9-17.

10. Atieh MA, Ibrahim HM, Atieh AH. Platform switching for marginal bone preservation around dental implants: a systematic review and meta-analysis. J Periodontol. 2010;81:1350-66.

11. Canullo L, Fedele GR, Iannello G, Jepsen S. Platform switching and marginal bone-level alterations: the results of a randomizedcontrolled trial. Clin Oral Implants Res. 2010;21:115-21.

12. Maeda Y, Miura J, Taki I, Sogo M. Biomechanical analysis on platform switching: is there any biomechanical rationale? Clin Oral Implants Res. 2007;18:581-4.

13. Rodríguez-Ciurana X, Vela-Nebot X, Segalà-Torres M, RodadoAlonso C, Méndez-Blanco V, Mata-Bugueroles M. Biomechanical repercussions of bone resorption related to biologic width: a finite element analysis of three implant-abutment configurations. Int J Periodontics Restorative Dent. 2009;29:479-87.

14. Huang HL, Huang JS, Ko CC, Hsu JT, Chang CH, Chen MY. Effects of splinted prosthesis supported a wide implant or two implants: a three-dimensional finite element analysis. Clin Oral Implants Res. 2005;16:466-72.

15. Hermann F, Lerner H, Palti A. Factors influencing the preservation of the periimplant marginal bone. Implant Dent. 2007;16:165-75.

16. Canullo L, Iurlaro G, Iannello G. Double-blind randomized controlled trial study on post-extraction immediately restored implants using the switching platform concept: soft tissue response. Preliminary report. Clin Oral Implants Res. 2009;20:414-20.

17. Schrotenboer J, Tsao YP, Kinariwala V, Wang HL. Effect of microthreads and platform switching on crestal bone stress levels: a finite element analysis. J Periodontol. 2008;79:2166-72.

18. Hoyer SA, Stanford CM, Buranadham S, Fridrich T, Wagner J, Gratton D. Dynamic fatigue properties of the dental implantabutment interface: joint opening in wide-diameter versus standarddiameter hex-type implants. J Prosthet Dent. 2001;85:599-607.

19. Brink J, Meraw SJ, Sarment DP. Influence of implant diameter on surrounding bone. Clin Oral Implants Res. 2007;18:563-8.

20. Chun HJ, Shin HS, Han CH, Lee SH. Influence of implant abutment type on stress distribution in bone under various loading conditions using finite element analysis. Int J Oral Maxillofac Implants. 2006;21:195-202. 